\title{
Design and simulation of an analog beamforming phased array antenna
}

\author{
Mohamed Elhefnawy \\ Department of Electrical Engineering, October 6 University, Egypt
}

\begin{tabular}{l} 
Article Info \\
\hline Article history: \\
Received Mar 1, 2019 \\
Revised Oct 10, 2019 \\
Accepted Oct 17, 2019 \\
\hline
\end{tabular}

\section{Keywords:}

Analog beamforming

Circular polarization

Phased array antenna

RF front-end

Slotted waveguide antenna

\begin{abstract}
In this paper, a phased array antenna is designed and simulated. The antenna array consists of four circularly polarized slotted waveguide elements. The antenna array is simulated using CST MWS. The simulation results for the proposed antenna array at different values of progressive phase shift demonstrate that the S-parameters for all four ports are less than $-10 \mathrm{~dB}$ over at least $2 \%$ bandwidth, the simulated maximum gain is $13.95 \mathrm{~dB}$, the simulated beamwidth can be $19^{\circ}$ or narrower based on the value of the progressive phase shift. The range of frequencies over which the simulated Axial Ratio (AR) is below $3 \mathrm{~dB}$ is not fixed and varied according to the selected progressive phase shift. The proposed four-element RF front-end is simulated using Advanced Design System (ADS) at operating frequency of $9.6 \mathrm{GHz}$. The obtained simulation results by ADS indicate the feasibility of implementing the proposed RF-front end for feeding the antenna array to realize analog beamforming.
\end{abstract}

Copyright (c) 2020 Institute of Advanced Engineering and Science. All rights reserved.

Corresponding Author:

Mohamed Elhefnawy,

Department of Electrical Engineering,

October 6 University,

6th of October City, Egypt.

Email: mmmelhefnawy.eng@o6u.edy.eg

\section{INTRODUCTION}

Phased array antenna with analog beamforming is regarded in order to improve the performance of wireless communication systems by increasing the coverage area and decreasing the interference. In analog beamforming technology, the phase of each signal received and transmitted by the antenna array element is adjusted, so that the radiation pattern of the antenna array is steered in the desired direction. The IF phase shifting is implemented in this research because it can provide much better performance compared to RF and LO phase shifting [1-14]. The slotted waveguide antenna array is selected because it can provide high power handling capability, low loss, small size, narrow beamwidth, good bandwidth, and high gain [15-25]. This paper is organized as follows. The design of the proposed antenna array element is explained in Section 2. The architecture of the proposed phased array system is introduced in Section 3. In Section 4, the simulation results are presented. The conclusions are provided in Section 5.

\section{DESIGN OF THE PROPOSED ANTENNA ARRAY ELEMENT}

For the proposed Slotted Waveguide Antenna Array (SWAA), the broad wall width of the rectangular waveguide is selected to make the cut-off frequency of $\mathrm{TE}_{10}$ mode is $86.9 \%$ of the operating frequency at $9.6 \mathrm{GHz}$. The narrow wall width of the rectangular waveguide is selected to be half the broad wall width. The waveguide wavelength $\left(\lambda_{g}\right)$ is calculated as [19] 


$$
\lambda_{g}=\frac{1}{\sqrt{\frac{1}{\lambda^{2}}-\frac{1}{\lambda_{c}^{2}}}}
$$

where $\lambda_{c}$ is the cutoff wavelength at the operating mode. There is a phase shift of $(\pi / 2)$ between the generated waves from the longitudinal slot fields (slot \#1 and slot \#3) and the wave produced by the transversal slot fields (slot \#2 and slot \#4). The Right Hand Circular Polarization (RHCP) is obtained by optimizing the slot offset from the central longitudinal line in order to change the value of $E_{L}$ to be equal to the value of $E_{T}$, where $E_{L}, E_{T}$ are magnitudes of the resultant waves from the longitudinal and transversal slot fields, respectively, as shown in Figure 1.

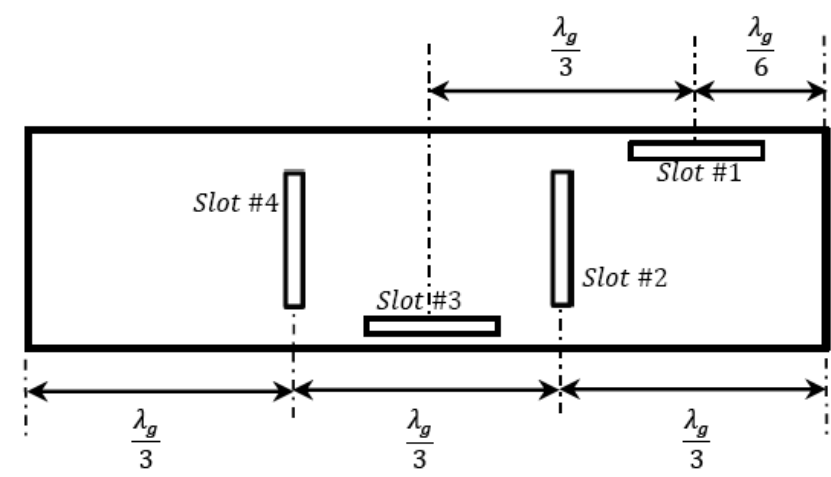

Figure 1. Structure of the resonating circularly polarized SWAA

\section{THE ARCHITECTURE OF THE PROPOSED PHASED ARRAY SYSTEM}

The proposed phased array antenna consists of four-element slotted waveguide antenna array and the RF front-end to feed the antenna array. The block diagram of the proposed phased array antenna is shown in Figure 2. In the receiving mode, the RF front-end has four channel; and two-stage down-conversion ( $9.6 \mathrm{GHz}$ to $2.4 \mathrm{GHz} \& 2.4 \mathrm{GHz}$ to $400 \mathrm{MHz}$ ). Also in the transmitting mode, there are other four channel; and two-stage up-conversion (400 MHz to $2.4 \mathrm{GHz} \& 2.4 \mathrm{GHz}$ to $9.6 \mathrm{GHz}$ ). Each channel in the receiving mode amplifies, down-converts $(9.6 \mathrm{GHz}$ to $2.4 \mathrm{GHz})$, adjusts the phase of, and demodulates the incoming signal from the antenna array element. The Wilkinson power combiner is used to combine the four signals coming from the antenna array to one signal which is entered to the I/Q demodulator to be down-converted again from $2.4 \mathrm{GHz}$ to $400 \mathrm{MHz}$. The demodulated (I\&Q) complex signals are fed to the input of the analog to digital converter (ADC). In the transmitting mode, the (I\&Q) signals from the digital to analog conversion (DAC) are modulated and up-converted from $400 \mathrm{MHz}$ to $2.4 \mathrm{GHz}$, then it is divided into four identical signals, each signal is transmitted through different channel, and its phase is adjusted then up-converted from $2.4 \mathrm{GHz}$ to $9.6 \mathrm{GHz}$, then it is filtered and amplified before transmitting to the antenna array element. The power detector is used to monitor the received signal power, and then the control part is implemented to change the progressive phase shift if the received power is lower than a threshold value. The antenna array is aligned in a $4 \times 1$ linear array with center to center distance between the adjacent elements of $0.705 \lambda$ as shown in Figures 3(a), and 3(b), the dimensions of the proposed slotted waveguide antenna element is indicated in Table 1.

Table 1. Dimensions of the Proposed Antenna Array Element

\begin{tabular}{ll}
\hline Parameter & Dimensions $(\mathrm{mm})$ \\
\hline Wavelength in the waveguide $\lambda_{\mathrm{g}}$ & 63.1875 \\
Broad-wall width of the rectangular waveguide & 18 \\
Narrow-wall width of the rectangular waveguide & 9 \\
Wavelength $\lambda$ & 31.25 \\
Slot length & 15.390625 \\
Slot width & 1.204 \\
Slot offset from the central longitudinal line & 7.447 \\
Monopole length & 7.8125 \\
\hline
\end{tabular}




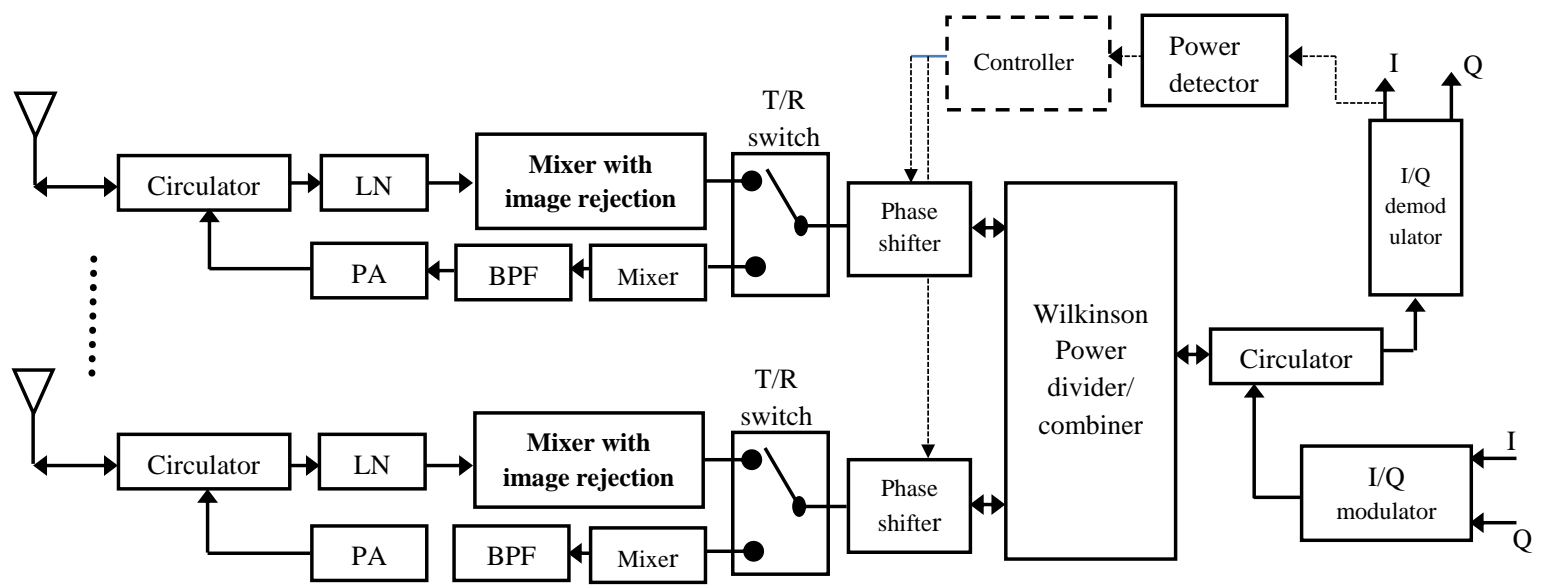

Figure 2. Block diagram of the proposed phased array antenna

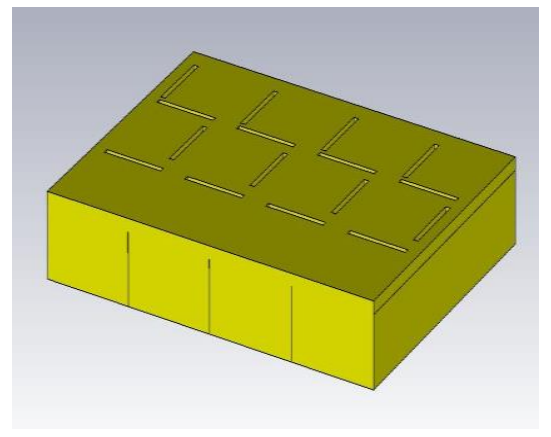

(a)

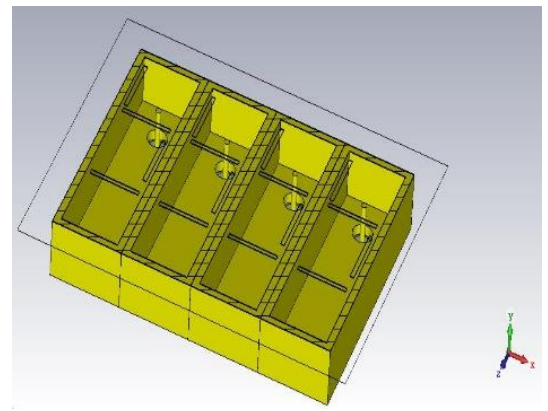

(b)

Figure 3. Geometry of the proposed SWAA: (a) Perspective view, (b) Cross-sectional plane view

\section{SIMULATION RESULTS}

The proposed antenna array is simulated using CST MWS, at an operating frequency of $9.6 \mathrm{GHz}$. The S-parameters for all four ports are below $-10 \mathrm{~dB}$ over frequency range from $9.5 \mathrm{GHz}$ to $9.7 \mathrm{GHz}$ as shown in Figure 4. The simulated two-dimensional and three-dimensional radiation patterns are shown in Figures 5 and 6 , respectively. The beam width is below $19^{\circ}$, and the antenna gain is at least $13.38 \mathrm{~dB}$.

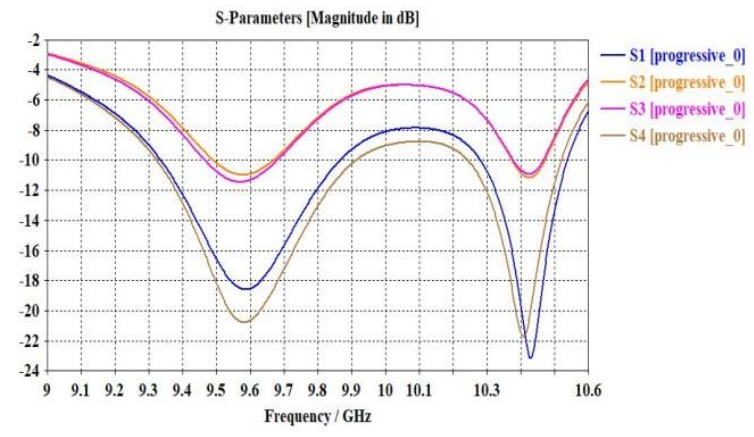

(a)

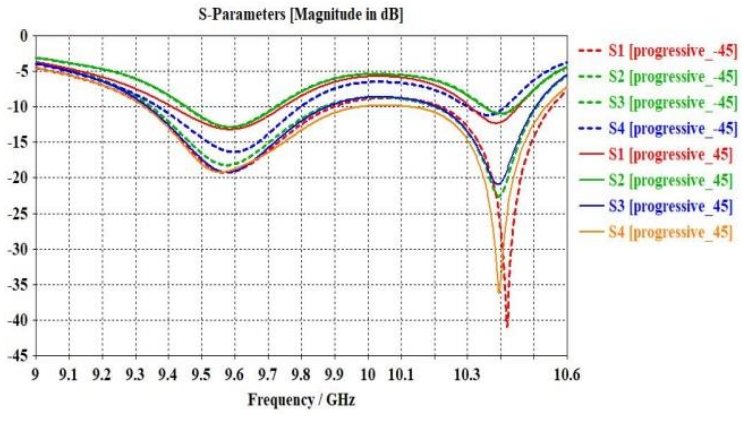

(b)

Figure 4. Simulated S-parameters for the proposed SWAA: (a) Progressive phase shift $=0^{\circ}$, (b) Progressive phase shift $= \pm 45^{\circ}$ 


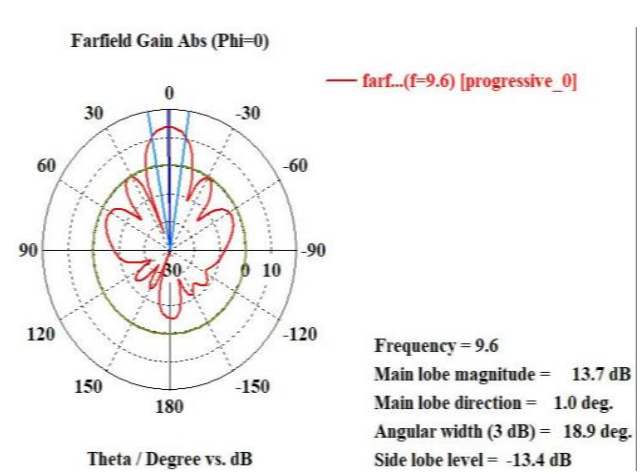

(a)

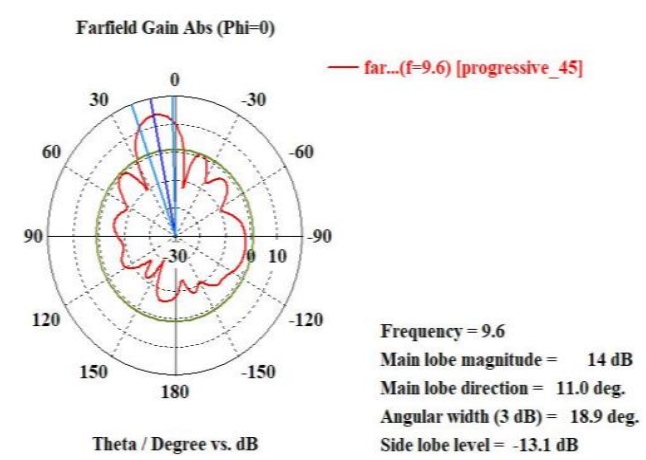

(b)

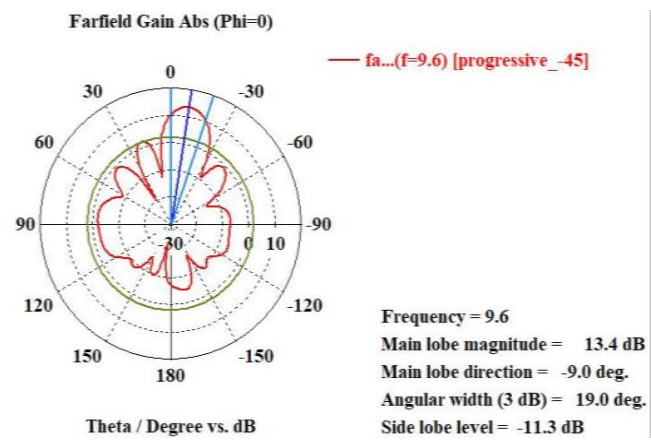

(c)

Figure 5. Simulate two-dimensional radiation pattern for the proposed SWAA: (a) Progressive phase shift $=0^{\circ}$, (b) Progressive phase shift $=45^{\circ}$, (c) Progressive phase shift $=-45^{\circ}$

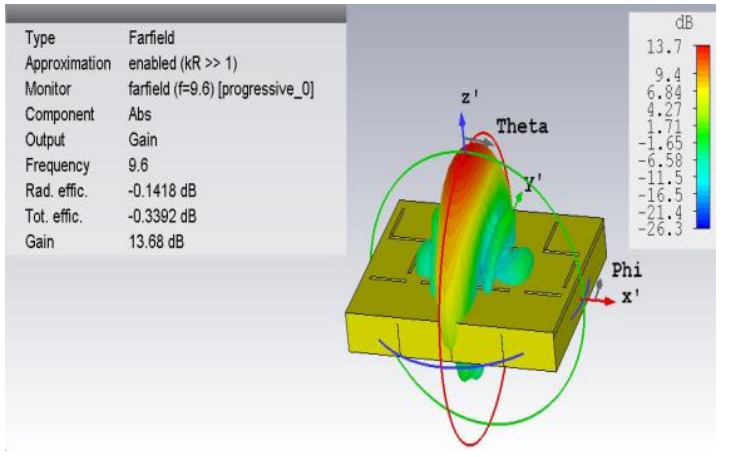

(a)

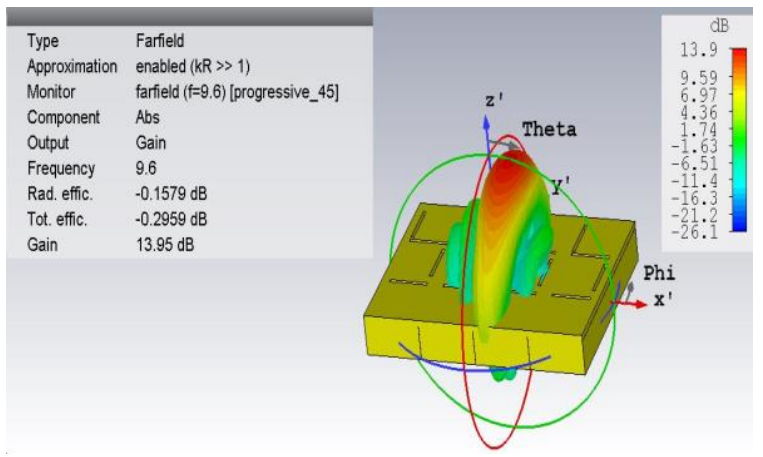

(b)

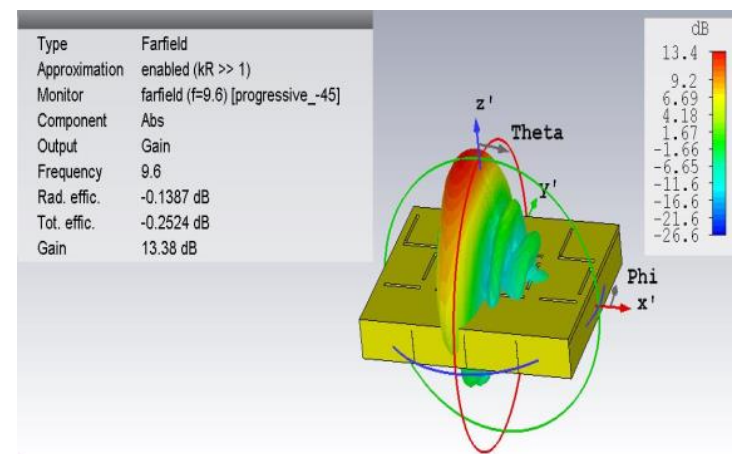

(c)

Figure 6. Simulated three-dimensional radiation pattern for the proposed SWAA; (a) Progressive phase shift $=0^{\circ}$, (b) Progressive phase shift $=45^{\circ}$, (c) Progressive phase shift $=-45^{\circ}$ 
The proposed antenna array is circularly polarized over frequency range from $9.5 \mathrm{GHz}$ to $9.7 \mathrm{GHz}$, but the purity of the circular polarization decreases as the progressive phase is far from $0^{\circ}$ as shown in Figure 7. The RF transceiver front-end is simulated using ADS as shown in Figure 8. In receiving mode, the incoming signal from each antenna array element is entered to any port of the circulator (TRAK Microwave Corporation X-Band SMT Circulator) to be transmitted to the next port in rotation, while the other port is isolated, then the signal is amplified by Mini-circuits PMA2-123LN+ low noise amplifier (LNA), and then it is down-converted from $9.6 \mathrm{GHz}$ to $2.4 \mathrm{GHz}$ by ANALOG DEVICES HMC1056LP4BE mixer. LNA is simulated by calling the S2P file of PMA2-123LN+ in the ADS. HMC1056LP4BE mixer consists of two balanced mixers and quadrature hybrid at the input, another quadrature hybrid is connected at its output to make this mixer works as an image rejection mixer which has the ability to select the desired signal and cancel out the image signal. One of these quadrature hybrids is designed at $9.6 \mathrm{GHz}$ and is used to split the RF input into inphase and quadrature signals, the other quadrature hybrid is designed at $2.4 \mathrm{GHz}$ and used to add 90 degrees phase shift between the two IF outputs before combining them together. The SPDT RF switch (Mini-circuits CSWA2-63DR+) is implemented to switch between the transmitting and receiving mode. The first stage IF signal $(2.4 \mathrm{GHz})$ is applied to the digital phase shifter (MACOM MAPS-010144), there is one digital phase shifter for each channel to adjust the progressive phase of the received signal in order to maximize the received signal power. This digital phase shifter is simulated in ADS by calling the S2P file. The $4 \times 1$ Wilkinson power divider/combiner is designed using ADS. The I/Q demodulator (ANALOG DEVICES ADRF6821) is simulated in ADS. A quadrature hybrid is designed at $2 \mathrm{GHz}$ to split the output from the local oscillator into two quadrature signals.

The outputs from I/Q demodulator are entered to the variable gain amplifier VGA (ANALOG DEVICES ADRF6520) to adjust this I/Q signals in order to fit within the input range of the next stage. If the I/Q signals are small, then the VGA will gain up these signals; while if it exceed that range, VGA will attenuate these I/Q signals. Also this VGA (ANALOG DEVICES ADRF6520) has a built in programmable filter to filter up the I/Q signals before ADC in order to prevent the aliasing content from being sampled. The frequency domain analysis is done by using Harmonic Balance (HB) simulation technique in ADS to determine the spectral contents for the RF receiver front-end. For I and Q channels at the output of I/Q demodulator, Figure 9 shows that the spectral with frequency $400 \mathrm{MHz}$ has maximum value and other spectral contents can be ignored. The I/Q output signals from the DAC is upconverted from $400 \mathrm{MHz}$ to $2.4 \mathrm{GHz}$ by using I/Q modulator (ANALOG DESVICES ADRF6821). The output from the I/Q modulator is divided into four signals by using $4 \times 1$ Wilkinson power divider, then the phase of each signal is adjusted, after that the signal is upconverted from $2.4 \mathrm{GHz}$ to $9.6 \mathrm{GHz}$ by using the mixer (ANALOG DEVICES HMC553ALC3B). VGA (ANALOG DEVICES HMC996LP4E) is used to fit the mixer's output to the input range of the next stage. The signal is passed through the band pass filter with center frequency $9.6 \mathrm{GHz}$ (K\&L Microwave, Inc 3FV20-9600/T300-SM/SM), then amplified by the power amplifier (ANALOG DEVICES HMC7149) before transmitted through the circulator to the antenna array element. The transmitter's variable gain amplifier, band pass filter, and power amplifier are simulated in ADS by calling their S2P files. Figure 10 shows the frequency domain analysis for the RF transmitter front-end at the inputs of the antenna array elements, where all spectral contents can be ignored compared to the spectral with frequency of $9.6 \mathrm{GHz}$.

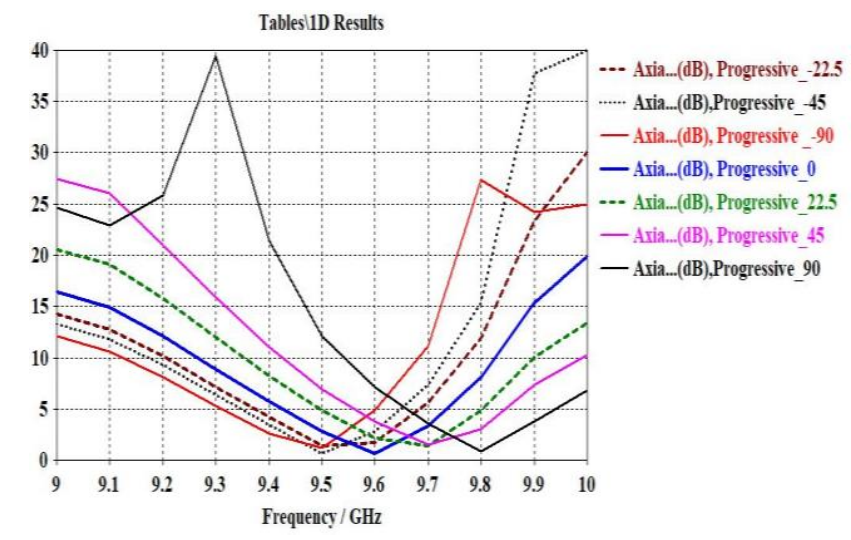

Figure 7. Simulated Axial Ratio (AR) versus frequency for the proposed SWAA at different values of the progressive phase shift 


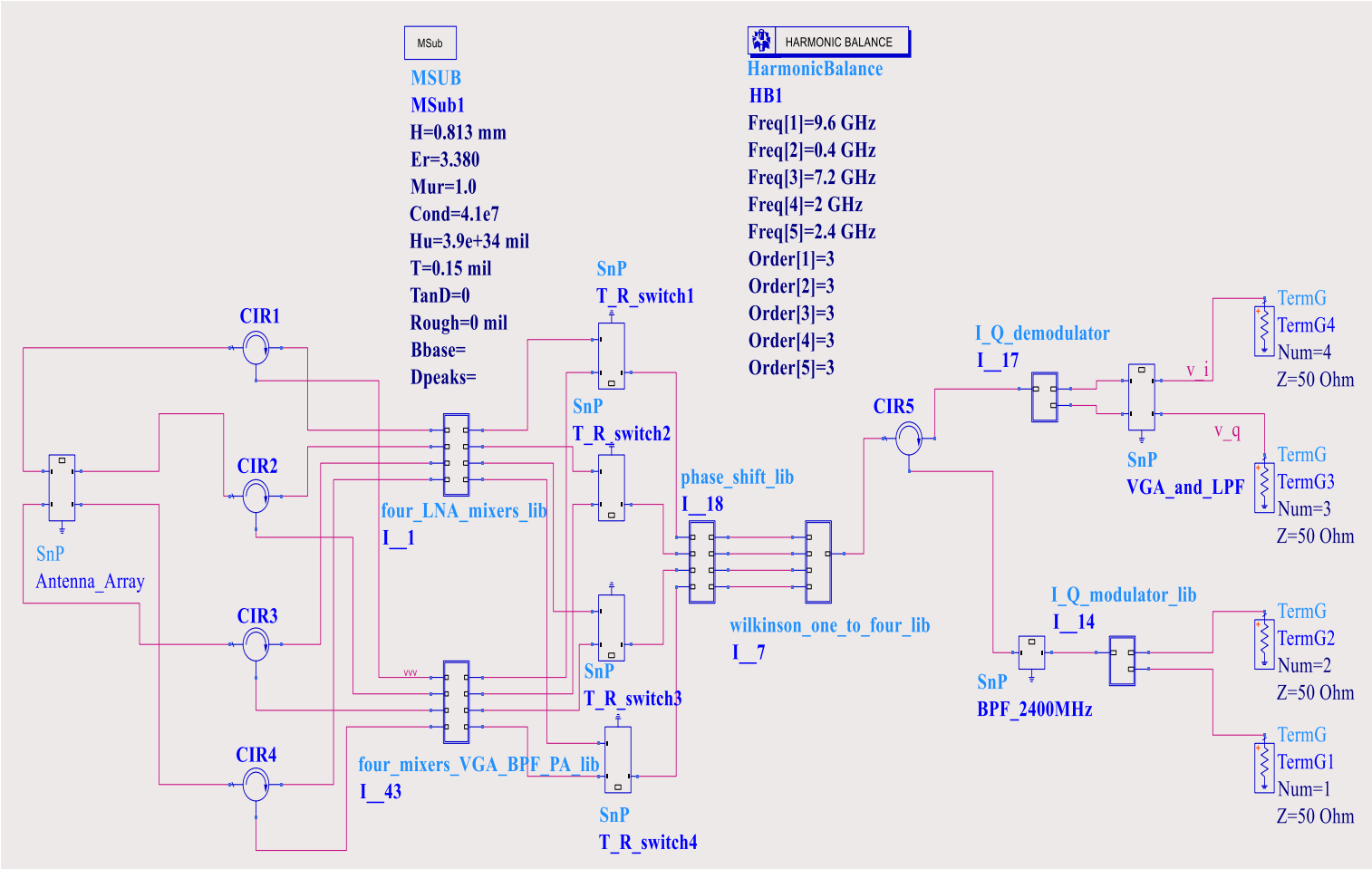

Figure 8. ADS simulation model for the proposed RF transceiver front-end
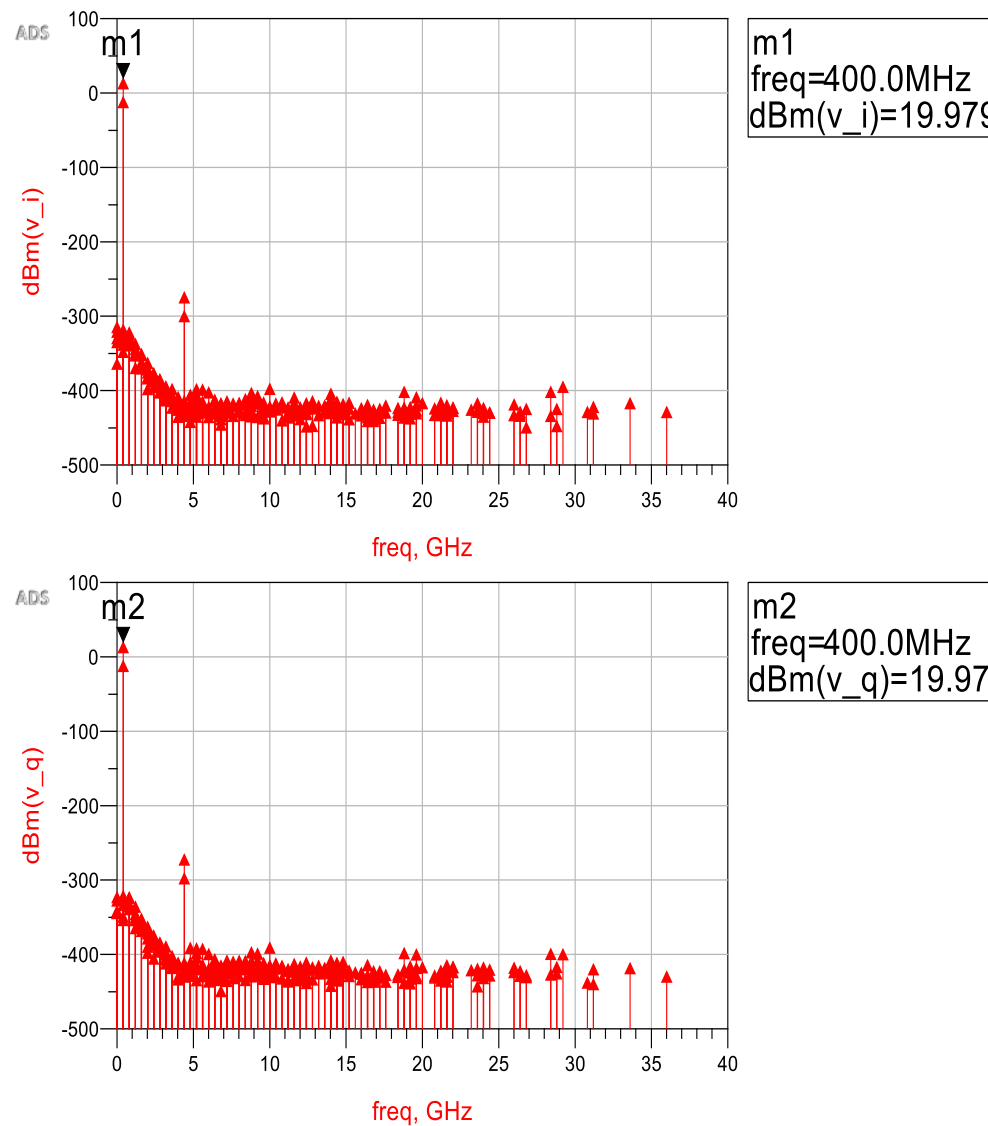

m2

freq $=400.0 \mathrm{MHz}$

$\mathrm{dBm}\left(\mathrm{v} \_\mathrm{q}\right)=19.977$

Figure 9. Frequency domain analysis at the output of I/Q demodulator for the RF receiver front-end 


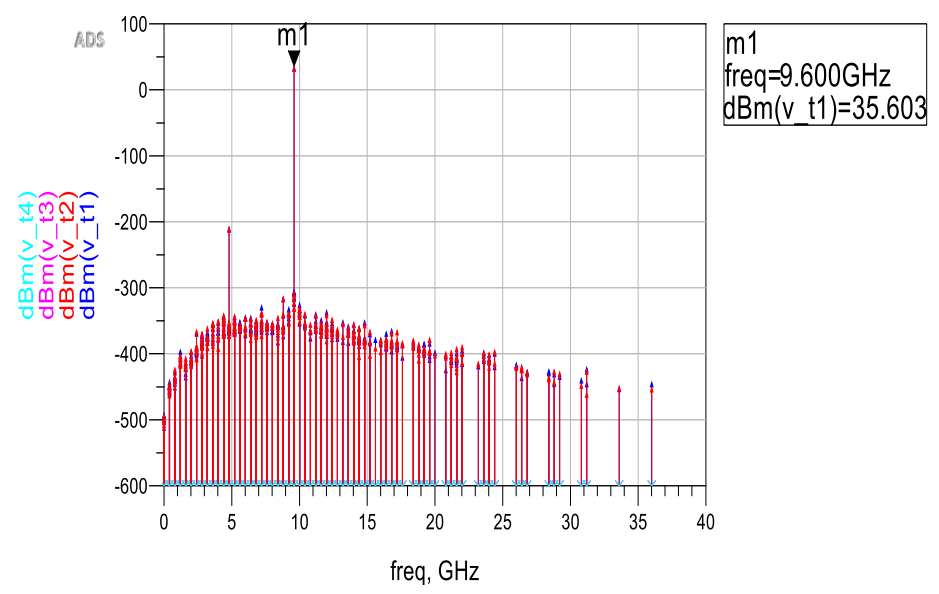

Figure 10. Frequency domain analysis at the inputs of the antenna array elements for the RF transmitter front-end

\section{CONCLUSION}

In this paper, the analog beamforming is realized by designing a proposed phased array antenna which operates at $9.6 \mathrm{GHz}$, and consists of $4 \times 1$ slotted waveguide antenna array with RF transceiver frontend as a feeder. The slotted waveguide antenna array is simulated in CST MWS; the simulation results show that the proposed phased array antenna can achieve a maximum gain of $13.95 \mathrm{~dB}$, a beam width equal or less than $19^{\circ}$ in the elevation plane, and S-parameters below-10 dB over the frequency range from $9.5 \mathrm{GHz}$ to $9.7 \mathrm{GHz}$. The purity of the circular polarization depends on the value of the progressive phase shift. The ADS simulation software is used to simulate the proposed RF transceiver front-end. The ADS simulation results show the possibility of using the proposed RF transceiver front-end as a feeder for the slotted waveguide antenna array to obtain analog beamforming at $9.6 \mathrm{GHz}$.

\section{REFERENCES}

[1] D. Ehyaie, "Novel Approaches to the Design of Phased Array Antennas," Doctor of Philosophy. The University of Michigan, 2011.

[2] G. L. Charvat, L. C. Kempel, E. J. Rothwell, C. M. Coleman, and E. L. Mokole, "An Ultrawideband (UWB) Switched-Antenna-Array Radar Imaging System," IEEE International Symposium on Phased Array Systems and Technology, Waltham, MA, pp. 543-550, 2010.

[3] M. T. Islam, N. Misran, and B. Yatim, "Smart Antenna UKM Testbed for Digital Beamforming System," EURASIP Journal on Advances in Signal Processing, 2009. DOI: 10.1155/2009/128516.

[4] W. Wang, J. Wang, D. Liang, Y. Tian, and T. Ren, "Development of RF Front-End for Real-Time MIMO Radar Imaging System," Sixth International Conference on Instrumentation \& Measurement, Computer, Communication and Control (IMCCC), Harbin, pp. 968-973, 2016.

[5] M. Hossu, S. H. Jamali, P. Mousavi, K. Narimani, M. Fakharzadeh, and S. Safavi-Naeini, "Microwave Beamforming using Analog Signal Processing," IEEE Antennas and Propagation Society International Symposium, San Diego, CA, pp. 1-4, 2008.

[6] N. A. Malek, O. O. Khalifa, Z. Z. Abidin, S. Y. Mohamad, and N. A. A. Rahman, "Beam Steering using the Active Element Pattern of Antenna Array," TELKOMNIKA, vol.16, no.4, pp. 1542-1550, August 2018.

[7] H. Xu, H. Aliakbarian, and G. A. E. Vandenbosch, "Off-the-Shelf Low-Cost Target Tracking Architecture for Wireless Communications," IEEE Systems Journal, vol. 9, no. 1, pp. 13-21, March 2015.

[8] R. Rotman, M. Tur, and L. Yaron, "True Time Delay in Phased Arrays," Proceedings of the IEEE, vol. 104, no. 3, pp. 504-518, March 2016.

[9] D. L. Lemes, M. V. T. Heckler, and A. Winterstein, "A Low-Cost Modular Transmit Front-End with Analog Beamforming Capability," SBMO/IEEE MTT-S International Microwave and Optoelectronics Conference (IMOC), Aguas de Lindoia, pp. 1-5, 2017.

[10] Y. Yao, F. Zhang and F. Zhang, "A New Approach to Design Circularly Polarized Beam-Steering Antenna Arrays Without Phase Shift Circuits," in IEEE Transactions on Antennas and Propagation, vol. 66, no. 5, pp. 2354-2364, May 2018.

[11] Y. Yashchyshyn, K. Godziszewski, G. Bogdan and P. Piasecki, "X-band antenna array for low-cost beam scanning," in IET Microwaves, Antennas \& Propagation, vol. 11, no. 15, pp. 2174-2178, 10122017.

[12] H. Zhu, H. Sun, B. Jones, C. Ding and Y. J. Guo, "Wideband Dual-Polarized Multiple Beam-Forming Antenna Arrays," in IEEE Transactions on Antennas and Propagation, vol. 67, no. 3, pp. 1590-1604, March 2019. 
[13] R. Baggen, S. Holzwarth, M. Bottcher and S. Otto, "Innovative Antenna Front Ends from L-Band to Ka-Band [Antenna Applications Corner]," in IEEE Antennas and Propagation Magazine, vol. 59, no. 5, pp. 116-129, Oct. 2017.

[14] A. S. Y. Poon and M. Taghivand, "Supporting and Enabling Circuits for Antenna Arrays in Wireless Communications," in Proceedings of the IEEE, vol. 100, no. 7, pp. 2207-2218, July 2012.

[15] M. W. Sabri, N. A. Murad, and M. K.A. Rahim, "Bi-directional Beams Waveguide Slotted Antenna at Millimeter Wave," TELKOMNIKA, vol. 16, no. 4, pp. 1515-1521, August 2018.

[16] A. Oliner, "The Impedance Properties of Narrow Radiating Slots in the Broad Face of Rectangular Waveguide: Part I--Theory," IRE Transactions on Antennas and Propagation, vol. 5, no. 1, pp. 4-11, January 1957.

[17] M. Orefice and R. S. Elliott, "Design of Waveguide-Fed Series Slot Arrays," Microwaves, Optics and Antennas, IEEE Proceedings H, vol. 129, no. 4, pp. 165-169, August 1982.

[18] R. K. Enjiu and Perotoni M. B., "Slotted Waveguide Antenna Design using 3D EM Simulation," Microwave Journal, Horizon House Publications, 2013.

[19] S. Rozenberg and A. Yahalom, "A THz Slot Antenna Optimization using Analytical Techniques," RADIOENGINEERING, vol. 25, no. 1. Sep. 2016.

[20] B. Pyne, P. R. Akbar, V. Ravindra, H. Saito, J. Hirokawa and T. Fukami, "Slot-Array Antenna Feeder Network for Space-Borne X-Band Synthetic Aperture Radar," in IEEE Transactions on Antennas and Propagation, vol. 66, no. 7, pp. 3463-3474, July 2018.

[21] P. Kumar, A. Kedar and A. K. Singh, "Design and Development of Low-Cost Low Sidelobe Level Slotted Waveguide Antenna Array in X-Band," in IEEE Transactions on Antennas and Propagation, vol. 63, no. 11, pp. 4723-4731, Nov. 2015.

[22] H. Guan-Long, Z. Shi-Gang, C. Tan-Huat and Y. Tat-Soon, "Broadband and high gain waveguide-fed slot antenna array in the Ku-band," in IET Microwaves, Antennas \& Propagation, vol. 8, no. 13, pp. 1041-1046, 21 October 2014.

[23] A. Ghasemi and J. Laurin, "A Continuous Beam Steering Slotted Waveguide Antenna Using Rotating Dielectric Slabs," in IEEE Transactions on Antennas and Propagation, vol. 67, no. 10, pp. 6362-6370, Oct. 2019.

[24] Y. Tyagi, P. Mevada, S. Chakrabarty and R. Jyoti, "High-efficiency broadband slotted waveguide array antenna," in IET Microwaves, Antennas \& Propagation, vol. 11, no. 10, pp. 1401-1408, 1682017.

[25] H. C. Zhao, R. R. Xu and W. Wu, "Broadband waveguide slot array for SAR," in Electronics Letters, vol. 47, no. 2, pp. 76-77, January 2011.

\section{BIOGRAPHY OF AUTHOR}

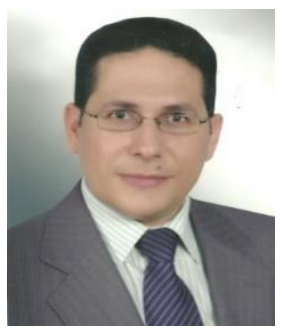

Mohamed Elhefnawy received $\mathrm{PhD}$ degree in Communications Engineering from USM University, Malaysia, in 2010. He has strong academic background that includes: RF/Microwave Engineering, Electromagnetic Theory and Antenna Theory. He has a particular set of skills in Electromagnetic simulation tools such as ADS and CST, and Simulation of Systems using MATLAB and Simulink. In addition to his expertise in antenna design, he has experience in designing and testing RF/Microwave components such as amplifiers, mixers, oscillators, and microwave filters. He got "Sanggar Sajung" Award for Excellence in Publishing, University of Science Malaysia (USM), 2009. He published high impact factor research papers. 